\title{
Minireview
}

Clinical

nephron

Practice

Published online: November 28, 2012

DOI: $\underline{10.1159 / 000345149}$

\section{Chronic Kidney Disease in the Arab World: A Call for Action}

\author{
Youssef M.K. Farag a Jameela A. Kari ${ }^{\text {a }}$ Ajay K. Singh ${ }^{\text {a }}$ \\ ${ }^{a}$ Renal Division, Brigham and Women's Hospital, Harvard Medical School, Boston, Mass., USA; \\ ${ }^{\mathrm{b}}$ Department of Pediatrics, Faculty of Medicine, King Abdulaziz University, Jeddah, Kingdom of Saudi Arabia
}

\begin{abstract}
Key Words
Chronic kidney disease $\cdot$ Diabetes $\cdot$ Hypertension •

Obesity · Screening programs • Arab league - Arab world •

Middle East
\end{abstract}

\begin{abstract}
Chronic kidney disease (CKD) is an emerging non-communicable disease worldwide. The Arab countries have a high prevalence of CKD risk factors, e.g. diabetes, obesity and hypertension. Unfortunately, the magnitude of CKD in the Arab world has not been studied well. This review presents the current data on CKD in the Arab world and proposes a call for action to address this rising epidemic.
\end{abstract}

Copyright $\odot 2012$ S. Karger AG, Basel

Much attention is now being directed to non-communicable diseases. As the world's population ages and the diabetes epidemic continues unabated, chronic kidney disease (CKD) is emerging as an important non-communicable disease worldwide [1]. The three very important risk factors for CKD - diabetes, hypertension and obesity - are highly prevalent in the Arab world, more so than perhaps anywhere else. However, the magnitude of CKD seems to have escaped the attention of policy makers and researchers insofar as this pertains to the 'Arab world'.

Progression of CKD to end-stage renal failure (ESRF) has tremendous human and economic implications. Mortality is as much as 17 -fold higher in patients with
ESRF compared to age- and gender-matched healthy individuals, and the cost of dialysis or transplantation is frequently unaffordable to many in the absence of governmental programs. Little attention and limited resources are being allocated to CKD and/or its risk factors even though the Arab world comprises 313.9 million people in 23 countries and territories spanning the two major continents of Africa and Asia. The situation needs to change because the current data underestimates the magnitude of the problem, which, if fully realized, will pose a tremendous burden to the public health system in these countries.

Data available on the exact prevalence of various kidney diseases in the Arab world is very limited. In reviewing the recent literature, we found that there is no Arab country with up-to-date information on the epidemiology of CKD. Most of the data come from small studies of approximately 100 patients or less (table 1). Based on their size and other design considerations, data from these studies have limited generalizability.

Diabetes and hypertension are the top two causes of ESRF in seven of twelve Arab countries (table 1). Remarkably, Arab countries such as the UAE, Saudi Arabia, Bahrain and Kuwait, where the World Health Organization (WHO) estimates 'very high prevalence of diabetes' (in the $15-25 \%$ range), there is a lack of accurate data on the CKD prevalence. In contrast, the American Diabetes Association estimates the diabetes prevalence in the USA to be about $8.3 \%$. The estimates for ESRF are a fraction of that reported in the USA where the incidence is 360 per

\section{KARGER}

Fax +4161306 1234

E-Mail karger@karger.ch

www.karger.com
(C) 2012 S. Karger AG, Basel

$1660-2110 / 12 / 1214-0120 \$ 38.00 / 0$

Accessible online at:

www.karger.com/nec
Dr. Ajay K. Singh, MD, MBA, FRCP

Brigham and Women's Hospital

Harvard Medical School

75 Francis Street, Boston, MA 02115 (USA)

E-Mail asingh@partners.org 
Table 1. Available data on the epidemiology of CKD and ESRF in the Arab world (data may date back as far as 1992 or be as recent as 2007)

\begin{tabular}{lccccc}
\hline Country & $\begin{array}{l}\text { Incidence of } \\
\text { CKD, pmp }\end{array}$ & $\begin{array}{l}\text { Incidence of } \\
\text { ESRF, pmp }\end{array}$ & $\begin{array}{l}\text { Prevalence } \\
\text { of ESRF, pmp }\end{array}$ & $\begin{array}{l}\text { Leading cause } \\
\text { of ESRF }\end{array}$ & $\begin{array}{l}\text { Second leading } \\
\text { cause of ESRF }\end{array}$ \\
\hline Algeria & - & 34 & 78.5 & - & - \\
Egypt & - & 74 & 375 & Diabetes & Hypertension \\
Jordan & - & 111 & 312 & Diabetes & Hypertension \\
Kuwait & 366 & 78 & 81 & Diabetes & GN \\
Libya & - & 200 & 30 & GN & - \\
Morocco & - & 60 & - & - & IN \\
Oman & - & 100 & 434 & GNpertension & Diabetes \\
Saudi Arabia & - & 100 & - & Diabetes & Obstructive uropathy \\
Sudan & - & 159 & - & GN & Hypertension \\
Tunisia & - & 74 & 480 & Giabetes \\
UAE & - & 122 & & Diabetes \\
Qatar & - & &
\end{tabular}

GN = Glomerulonephritis; IN = interstitial nephritis.

million population (pmp) and the prevalence is 1,626 pmp [2]. Unless the likelihood of developing ESRF is dramatically lower in the Arab world than that in western countries, these lower reported prevalence and incidence data in Arab countries most probably reflect underreporting and/or the lack of properly designed national renal registries. In addition, many patients with untreated and possibly undiagnosed ESRF are not counted. This could result in underestimating the incidence and prevalence of ESRF.

Diabetes, hypertension and obesity are powerful risk factors in the etiology of CKD. Extrapolations based on the epidemiology of these risk factors may provide some insights into the epidemiology of CKD. In 2007, according to the WHO, four out of the top five countries with diabetes were high-income countries from the Arab world [ 3 , 4]. With the exception of Nauru, which had a prevalence of diabetes mellitus in its adult population of $30.7 \%$, the UAE (19.5\%), Saudi Arabia (16.7\%), Bahrain (15.2\%) and Kuwait (14.4\%) represent focal points for diabetes. Table 2 depicts the estimated prevalence of diabetes in 2000 and the expected data in 2030 in the Arab countries and US.

Most individuals with diabetes in low- and middleincome countries are middle aged (45-64) and elderly (>65 years). In Jordan, Libya, Morocco and Oman, data shows that the prevalence of diabetes has increased from approximately $3 \%$ prior to 1980 to a current prevalence of $5-16 \%$ (prevalence exceeding $10 \%$ of the adult population) [5]. In Jordan, the leading cause of ESRF was reported to be diabetes (29.2\%). In the UAE $23.3 \%$ of patients
Table 2. The estimated prevalence of diabetes in 2000 and the expected number in 2030 in the world, the USA and Arab countries for which information is available [4]

\begin{tabular}{lrr}
\hline Country & \multicolumn{2}{c}{2000} \\
\hline World & $171,000,000$ & $366,000,000$ \\
USA & $17,702,000$ & $30,312,000$ \\
Arab World & $7,814,000$ & $22,157,000$ \\
Algeria & 426,000 & $1,203,000$ \\
Bahrain & 37,000 & 99,000 \\
Comoros & 4,000 & 15,000 \\
Djibouti & 7,000 & 9,000 \\
Egypt & $2,623,000$ & $6,726,000$ \\
Iraq & 668,000 & $2,009,000$ \\
Jordan & 195,000 & 680,000 \\
Kuwait & 104,000 & 319,000 \\
Lebanon & 146,000 & 378,000 \\
Libya & 88,000 & 245,000 \\
Mauritania & 34,000 & 103,000 \\
Morocco & 427,000 & $1,138,000$ \\
Oman & 113,000 & 343,000 \\
Qatar & 38,000 & 88,000 \\
Saudi Arabia & 890,000 & $2,523,000$ \\
Somalia & 97,000 & 331,000 \\
Sudan & 447,000 & $1,277,000$ \\
Syria & 627,000 & $2,313,000$ \\
Tunisia & 166,000 & 388,000 \\
UAE & 350,000 & 684,000 \\
Yemen & 327,000 & $1,286,000$ \\
\hline & & \\
\hline
\end{tabular}


with ESRF had diabetes as the cause. Therefore, collectively, since $30 \%$ of individuals with diabetes develop kidney failure, it is likely that diabetic kidney disease is a significant, albeit relatively underreported, burden in the Arab world.

Likewise, the prevalence of hypertension, its level of public awareness and hypertension risk factors are poorly understood in the Arab world. Hypertension is both a cause and a complication of CKD since $>50 \%$ of patients with CKD have hypertension (blood pressure $>140 / 90$ $\mathrm{mm} \mathrm{Hg}$ ). In addition, hypertension is a risk factor for progression of kidney disease and cardiovascular diseases. In the National Hypertension Project (NHP) in Egypt [6, 7], the national estimate of the prevalence of hypertension in Egyptians was 26.3\%. Only 37.5\% of the hypertensive individuals were aware of being hypertensive. Hypertension is also responsible for $28 \%$ of causes of ESRF in Egypt [8]. In Saudi Arabia, the prevalence of hypertension varied between different studies in part because there was variability in how hypertension was defined. In one study, the prevalence of hypertension in Saudi Arabia was $15.2 \%$ [9], while in another study, also by Al-Nozha et al. [10], in 2007 the prevalence of hypertension was $26.1 \%$.

The reported prevalence of hypertension in the UAE and Syria has varied because of different criteria for defining hypertension. In 1999, the reported prevalence in the UAE was $36.6 \%$ [11]. In a cross-sectional communitybased study in Al-Ain in the UAE, of 817 participants $20.8 \%$ had hypertension [12]. In 2007, Syrian investigators reported a $40.6 \%$ prevalence of hypertension, which was higher among men [13]. These disparate observations could be explained by small sample sizes and/or different definitions of hypertension. This is supported by a recent report of the under-diagnosis (33\%) and undertreatment (76\%) of hypertension in the UAE [14].

Obesity is also related to CKD epidemiology since obesity appears to be an important risk factor for CKD [16-20]. The prevalence of obesity has increased over the past 2 decades. Over 3,000 million adults worldwide are obese [21]. The prevalence of a body mass index of at least 35 among incident dialysis patients has increased by $64 \%$ over the past decade, and if trends continue $20 \%$ of all patients will initiate dialysis with this degree of obesity. In Syria, obesity was found to be $38.2 \%$, with the prevalence in women nearly one and half times more than in men [13]. Obesity affects $16-50 \%$ of individuals with diabetes in the Arab world, 20-38\% have hyperlipidemia, 24-46\% have hypertension and, although data are incomplete, nephropathy and retinopathy rates appear to be quite high $[5,22]$. Moreover, in a review of obesity prevalence in the Arab world [23] it was concluded that one-third of Arabs are obese and women have particularly higher rates of obesity as defined by a body mass index of 30 .

In summary, even though the data is limited, the evidence points to a high prevalence of three of the major risk factors for CKD in the Arab world, which implies that this population has a significant risk for developing CKD. Unfortunately, the lack of epidemiologic data on CKD is a key stumbling block to highlighting the importance of this problem among policy makers. On the other hand, it is important to mention the recent findings of the U.S. Preventive Services Task Force (USPSTF) that there is not enough evidence to show that screening healthy adults for CKD improves outcomes [24]. Additionally, it shows that the balance of benefits and harms cannot be determined, and subsequently, the screening of healthy adults with asymptomatic CKD is not advisable.

\section{A Call for Action}

There is an urgent need to conduct proper epidemiologic studies on CKD in the Arab world. Many Arab countries do have the resources and the public health infrastructure to do such work - Egypt, Saudi Arabia and the UAE being prime examples. Furthermore, screening programs in CKD are relatively inexpensive as we have demonstrated in Saudi Arabia [25] and elsewhere. We believe policy makers and clinicians should consider emphasizing CKD as a public health problem and devote resources to it especially since money is now being made available for research. This will bring Arab countries in line with other middle- to high-income nations. To this point, the budget for research in the Arab world is approximately $0.15 \%$ of GDP, compared with an average of $1.4 \%$ in the world and $2.5 \%$ in Europe. While we recognize that resources, lack of awareness, cultural and social issues may have contributed to the absence of studies on CKD in the Arab world, the past should not be a prologue to what must happen in the future.

\section{Disclosure Statement}

The authors report no support from any organization for the submitted work, no financial relationships with any organizations that might have an interest in the submitted work in the previous 3 years and no other relationships or activities that could appear to have influenced the submitted work. 


\section{References}

1 Levey AS, Atkins R, Coresh J, Cohen EP, Collins AJ, Eckardt KU, Nahas ME, Jaber BL, Jadoul M, Levin A, Powe NR, Rossert J, Wheeler DC, Lameire N, Eknoyan G: Chronic kidney disease as a global public health problem: approaches and initiatives - a position statement from Kidney Disease Improving Global Outcomes. Kidney Int 2007;72: 247-259. http://www.kdigo.org/pdf/Levey_ KI_2007.pdf (accessed May 18, 2012).

2 USRDS 2008 Annual Data Report: Atlas of Chronic Kidney Disease and End-Stage Renal Disease in the United States. Bethesda, NIH, 2008.

3 International Federation of Diabetes: Facts and figures. http://www.idf.org/home/index.cfm?node $=6$ (accessed March 17, 2009).

4 WHO: Diabetes programme. http://www. who.int/diabetes/en/ (accessed March 17, 2009).

5 Albach NM: Increased prevalence rate of diabetes mellitus and associated risk factors in the Arab world. Poster 1364, presented at the 18th International Diabetes Federation Congress, Paris, August 24-29, 2003.

6 6 Ashour Z, Ibrahim MM, Appel LJ, Ibrahim AS, Whelton PK: The Egyptian National Hypertension Project (NHP): design and rationale - the NHP investigative team. Hypertension $1995 ; 26: 880-885$.

7 Ibrahim MM, Rizk H, Appel LJ, el Aroussy W, Helmy S, Sharaf Y, et al: Hypertension prevalence, awareness, treatment, and control in Egypt: results from the Egyptian $\mathrm{Na}-$ tional Hypertension Project (NHP) - NHP investigative team. Hypertension 1995;26: 886-890.

8 Afifi A, Karim MA: Renal replacement therapy in Egypt: first annual report of the Egyptian Society of Nephrology, 1996. East Mediterr Health J 1999;5:1023-1029.
9 Al-Nozha MM, Ali MS, Osman AK: Arterial hypertension in Saudi Arabia. Ann Saudi Med 1997;17:170-174.

10 Al-Nozha MM, Abdullah M, Arafah MR, Khalil MZ, Khan NB, Al-Mazrou YY, et al: Hypertension in Saudi Arabia. Saudi Med J 2007;28:77-84.

11 El-Shahat YI, Bakir SZ, Farjou N, Hashim T, Bohaliga A, Al-Hossani H, et al: Hypertension in UAE citizens - preliminary results of a prospective study. Saudi J Kidney Dis Transpl 1999;10:376-381.

12 Baynouna LM, Revel AD, Nagelkerke NJ, Jaber TM, Omar AO, Ahmed NM, et al: High prevalence of the cardiovascular risk factors in Al-Ain, United Arab Emirates: an emerging health care priority. Saudi Med J 2008;29: 1173-1178.

13 Maziak W, Rastam S, Mzayek F, Ward KD, Eissenberg T, Keil U: Cardiovascular health among adults in Syria: a model from developing countries. Ann Epidemiol 2007;17: 713-720.

14 Abdulle AM, Nagelkerke NJ, Abouchacra S, Pathan JY, Adem A, Obineche EN: Undertreatment and under diagnosis of hypertension: a serious problem in the United Arab Emirates. BMC Cardiovasc Disord 2006;6: 24.

15 Nazim Uddin K: Prevalence of hypertension in Saudi Arabia. Practitioner East Mediterr Ed 1994;11:805-806.

16 Ferris M, Hogan SL, Chin H, Shoham DA, Gipson DS, Gibson K, et al. Obesity, albuminuria, and urinalysis findings in US young adults from the Add Health Wave III study. Clin J Am Soc Nephrol 2007;2:12071214.

17 Elsayed EF, Sarnak MJ, Tighiouart H, Griffith JL, Kurth T, Salem DN, et al: Waistto-hip ratio, body mass index, and subsequent kidney disease and death. Am J Kidney Dis 2008;52:29-38.
18 Elsayed EF, Tighiouart H, Weiner DE, Griffith J, Salem D, Levey AS, et al: Waist-tohip ratio and body mass index as risk factors for cardiovascular events in CKD. Am J Kidney Dis 2008;52:49-57.

19 Foster MC, Hwang SJ, Larson MG, Lichtman JH, Parikh NI, Vasan RS, et al: Overweight, obesity, and the development of stage 3 CKD: the Framingham Heart Study. Am J Kidney Dis 2008;52:39-48.

20 Alexander MP, Patel TV, Farag YM, Florez A, Rennke HG, Singh AK: Kidney pathological changes in metabolic syndrome: a cross-sectional study. Am J Kidney Dis 2009;53:751759.

21 WHO: Obesity: preventing and managing the global epidemic - report of a WHO consultation. Geneva, WHO, 2003.

22 Diabetes in the Arab World. www.arabdiabetes.org (accessed March 17, 2009).

23 al-Mahroos F, al-Roomi K: Overweight and obesity in the Arabian Peninsula: an overview. J R Soc Health 1999;119:251-253.

24 Moyer VA: Screening for chronic kidney disease: US Preventive Services Task Force Recommendation Statement. Ann Intern Med 2012, E-pub ahead of print.

-25 Alsuwaida AO, Farag YM, Al Sayyari AA, Mousa D, Alhejaili F, Al-Harbi A, Housawi A, Mittal BV, Singh AK: Epidemiology of chronic kidney disease in the Kingdom of Saudi Arabia (SEEK-Saudi investigators) - a pilot study. Saudi J Kidney Dis Transpl 2010; 21:1066-1072.

26 Abolfotouh MA, Soliman LA, Mansour E, Farghaly M, El-Dawaiaty AA: Central obesity among adults in Egypt: prevalence and associated morbidity. East Mediterr Health J 2008; 14:57-68. 